\title{
Liquid kit for Preparation of ${ }^{188}$ rhenium-etidronate
}

\author{
Barbara Marczewski ${ }^{*}$, Carla Roberta Dias, Vanessa Moraes and João Alberto Osso Junior \\ Centro de Radiofarmácia; Instituto de Pesquisas Energéticas e Nucleares - IPEN-CNEN/SP; Av. Prof. Lineu \\ Prestes, 2242; 05508-900; baszot@gmail.com; São Paulo - SP - Brasil
}

\begin{abstract}
The aim of this study was the preparation of a liquid kit for radiolabeling of ${ }^{188}$ Re-HEDP (hydroxyethylidene diphosphonate). ${ }^{188}$ Re was obtained from alumina based ${ }^{188}{ }^{1 / 88}$ Re generators. This paper reports the efficacy of a cold kit stored for more than two weeks, determined by the dependence of the radiolabeling yields of ${ }^{188} \operatorname{Re}-H E D P$ on the incubation time, reducing agent concentration, the effects of concentration of ligand, the pH of the reaction and the temperature. The cold kits showed a good stability when carrie-free rhenium-188 was added in the reaction mixture.
\end{abstract}

Key words: Rhenium-188 HEDP, Liquid Kit, Radiolabeling.

\section{INTRODUCTION}

Bone-seeking radiopharmaceuticals have been well studied, including phosphorus-32, strontium89, samarium-153, and rhenium-186/188. Rhenium-188 is an attractive alternative for therapeutic use because of its 16.9-hour half-life. Its maximum beta-energy is $2.1 \mathrm{MeV}$ with a $15 \%$ abundance of gamma ray emission $(155 \mathrm{keV})$. (Verdera et al, 1997, Lin et al., 1997; Atkins, 1998; Palmedo et al., 2000; Bagatti et al., 2005)

${ }^{188} \mathrm{Re}$ is produced by double neutron capture on a ${ }^{186} \mathrm{~W}$ target to form ${ }^{188} \mathrm{~W}$ which decays with a 69 day half-life to ${ }^{188} \mathrm{Re}$. Recently, the routine availability of ${ }^{188} \mathrm{~W}-{ }^{188} \mathrm{Re}$, which provides high levels of ${ }^{188} \mathrm{Re}$ in low volumes, has been reported (Knapp et al., 1997, Knapp, 1998).

The chemistry of rhenium closely resembles technetium chemistry because both elements exist in group VIIa of the periodic table, providing analogy to ${ }^{99 m}$ Tc-complex formation. However, rhenium complexes have a higher tendency to be reoxidized back to perrenate than do the analogous technetium complexes (Kotari et al., 1999).

Biphosphonates are an attractive alternative for bone pain palliation, which is currently in clinical use as conventional analgesics or external beam radiation (Hashimoto, 1998; Hsieh, 1999; Lam et al., 2004). The purpose of this work is to describe a convenient preparation of cold kits to label HEDP with ${ }^{188}$ Re.

\section{MATERIALS AND METHODS}

Carrier-free ${ }^{188} \mathrm{Re}$ was eluted with $0.9 \% \mathrm{NaCl}$ from alumina-based ${ }^{188} \mathrm{~W}-{ }^{188} \mathrm{Re}$ generators $(1.85 \mathrm{x}$ $10^{10} \mathrm{~Bq}$ ), without the bolus concentrator components, supplied from Oak Ridge National Laboratory (ORNL). Quality control of carrierfree $\mathrm{Na}^{188} \mathrm{ReO}_{4}$ was performed using ITLC-SG chromatographic strips developed with saline.

\footnotetext{
Author for correspondence
} 


\section{Preparation of ${ }^{188} \mathrm{Re}-\mathrm{HED}$}

The "Kits" were designed to contain 170 or 300 $\mathrm{mg}$ of $\mathrm{Na}_{2} \mathrm{HEDP}, 30 \mathrm{mg}$ of ascorbic acid and 70 $\mathrm{mg}$ of $\mathrm{SnCl}_{2} \cdot 2 \mathrm{H}_{2} \mathrm{O}$ as a reducing agent. The first two components were dissolved in $10 \mathrm{~mL}$ of water for injection. The solution was added to the vial with the reducing agent and stirred during the addition until a clear colorless solution ( $\mathrm{pH}$ about 1.5) was obtained (Knapp et al., 1997).

The amount of kit required to maximize the results of radiolabeling (1-2 mL) was evaluated. In some kits, $2 \mathrm{~mL}$ of $0.3 \mathrm{M}$ sodium acetate trihydrate was added to neutralize the solution $(\mathrm{pH} \mathrm{5)}$. The time of incubation was 60 and 180 minutes. In some cases, the mixture was heated in a boiling water bath (30 minutes) before allowing the mixture to cool to room temperature.

A combination of two paper radiochromatography methods was used for the quality control of the radiolabeled products: a) the ITLC-SG developed with saline as mobile phase to separate the reduced hydrolyzed $\left[\mathrm{Re}^{\mathrm{IV}}\right]$ that remained at the origin from
${ }^{188}$ Re-HEDP and $\mathrm{ReO}_{4}{ }^{-}$anions; b) Whatman No. 1 paper developed with acetone, where the ${ }^{188} \mathrm{Re}$ HEDP and the hydrolyzed $\mathrm{Re}^{\mathrm{IV}}$ species remained at the origin and $\mathrm{ReO}_{4}{ }^{-}$migrated with the solvent front.

The samples were spotted at $1.5 \mathrm{~cm}$ from the bottom of the paper strip and developed in the two systems until the mobile phase reached the solvent front of the strip $(10 \mathrm{~cm})$. After drying, the strips were cut into two parts, $5 \mathrm{~cm}$ from the spot point. The activity distributions were measured with a HPGe detector to calculate the labeling yield efficiency.

\section{RESULTS AND DISCUSSION}

It was necessary to reduce ${ }^{188} \mathrm{Re}$ to perrhenate with an ideal molar excess of stannous chloride. The determination of the concentration of $\mathrm{SnCl}_{2}$ in the kit formulation is shown in Fig 1.

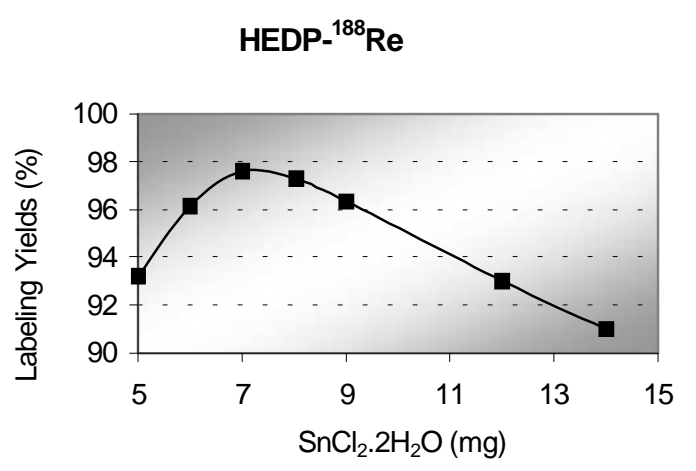

Figure 1 - Labeling of ${ }^{188}$ Re-HEDP in relation to the mass of stannous chloride.

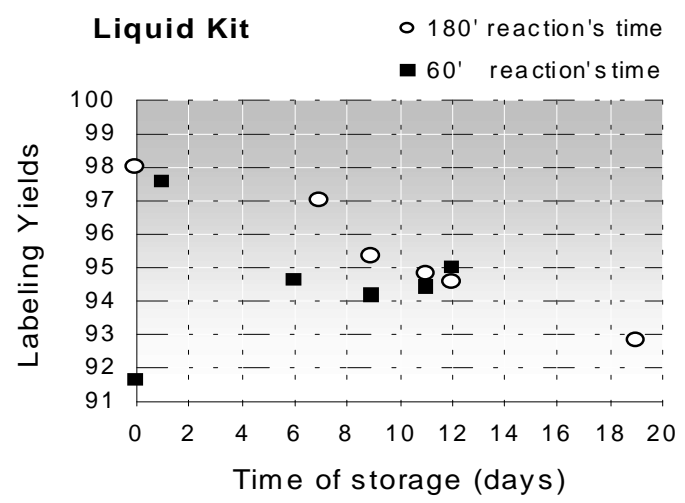

Figure 2- Labeling yields of ${ }^{188} \mathrm{Re}-\mathrm{HEDP}$ after a storage period protected from light. 
The product that was prepared with $30 \mathrm{mg}$ of HEDP and $7 \mathrm{mg}$ of $\mathrm{SnCl}_{2}$ showed the best results, with $98 \%$ of RC purity at the end of 60 minutes in the complexation reaction without heating bath. Under the same conditions, the formulation with $17 \mathrm{mg}$ of HEDP yielded a product with $91 \%$ RC purity.

The effect of $\mathrm{pH}$ on the complexation yield was studied by carrying out the reaction at $\mathrm{pH} 1.5$ (yielding $98 \%$ ) and $\mathrm{pH} 5-6$. Adding a nonpurged buffer that gave a smaller complexation yield $(\sim 79 \%)$ caused by a faster decomposition and an accumulation of ${ }^{188} \mathrm{ReO}_{4}^{-}$. The complexation yield reached a maximum at $\mathrm{pH} 1.5$, but a yield of $91 \%$ was obtained after adjusting the $\mathrm{pH}$ to 5 by purging $\mathrm{N}_{2}$ to the acetate buffer.

Heating the reaction mixture in boiling water for 30 minutes at $\mathrm{pH} 1.5$ yielded $95 \%$ of complex formation, and no increase in the labeling yield was observed by heating the reaction complex. However, the duration of the reaction was important for obtaining good results. The results in Fig. 2 showed that, after three hours of incubation, a better stability of the complexes and an increase in the labeling yields ( $98 \%)$ of the Liquid Kit were obtained when fresh formulations (0 days storage) were used and about $95 \%$ when the formulations were used after more than a week (nine days) of storage.

Two kits were made for comparison to determine the importance of the ligand mass. The results demonstrate that $17 \mathrm{mg}$ of HEDP or $30 \mathrm{mg}$ of HEDP had very similar yields under the same conditions.

The same formulation with $30 \mathrm{mg}$ HEDP was prepared and, after all the contents had been dissolved in distilled water, one $\mathrm{mL}$ aliquots of this solution were dispensed using a sterile syringe by filtering through a sterile $0.22 \mu \mathrm{m}$ Millipore filter into sterile dose vials and freeze dried to prepare lyophilized kits. However, even with the lyophilization process, the kit did not become completely dry, resulting in low yields $(94 \pm 1 \%)$ and a product of much lower stability compared to that of the liquid kit. One advantage of using liquid kits is the ease of preparation by simply adding the reagents to promote a clear colorless solution without using inert atmospheres, thus achieving higher yields and providing an available kit to be used for direct addition of the rhenium188 without heating.

\section{CONCLUSIONS}

The formulation of a liquid kit that provided very good labeling results was studied. The labeling was influenced by $\mathrm{pH}$ and time of incubation to form the complexes. The need for purging with $\mathrm{N}_{2}$ and the addition of buffer solutions after the reaction was complete is related to the fast decomposition of the complexes. In this way, an accumulation of free-rhenium is inhibited, giving more stability to the products. The liquid kit can be stored for at least for nine days without affecting the radiolabeling yields ( $95 \%$, considered a good result for a kit). An additional study to be made involves the freezing of the liquid kits to increase the storage stability of the kits with smaller decreases in the labeling yield.

\section{ACKNOWLEDGEMENTS}

The research at IPEN was supported by the Conselho Nacional de Desenvolvimento Científico e Tecnológico (CNPq - Brazil). The authors express thanks to the colleagues and collaborators at IPEN.

\section{RESUMO}

O objetivo desse trabalho é a preparação de um kit líquido para a radiomarcação do ${ }^{188}$ Re-HEDP (hidroxietilideno - difosfonato). $\mathrm{O}{ }^{188} \mathrm{Re}$ foi obtido por meio do gerador ${ }^{188} \mathrm{~W}^{\prime 188} \mathrm{Re}$ em alumina. Este trabalho reporta a experiência do preparo de um kit frio armazenado por até duas semanas. Os parâmetros estudados para obter melhores rendimentos de marcação do ${ }^{188}$ Re-HEDP foram: o tempo de incubação, a concentração do agente redutor, massa do ligante, o $\mathrm{pH}$ e a temperatura da reação. $\mathrm{O}$ kit frio mostrou uma boa establidade quando o ${ }^{188}$ Re livre de carregador foi adicionado na mistura de reação. 


\section{REFERENCES}

Verdera, E.S.; Gaudiano, J.; León, A.; Martinez, G.; Robles, A.; Savio, E.; León, E.; McPherson, D.W., Knapp, FF(Russ)Jr.; (1997), Rhenium-188-HEDP kit formulation and quality control. Radiochimica Acta, 79, 113-117.

Lin, W-Y.; Lin, C-P.; Yeh, S-J.; Hsieh, B-.T.; Tsai, ZT.; Ting, G.; Yen, T-C.; Wang, S-J.; Knapp, FF(Russ)Jr.; Stabin, M.G.; (1997), Rhenium-188 hydroxyethylidene diphosphonate: a new generatorproduced radiotherapeutic drug of potential value for the treatment of bone metastases. Eur. J. Nucl. Medicine, 24, 590-595.

Atkins, H.; (1998), Overview of nuclides for bone pain palliation. Appl. Radiat. Isotopes, 49, 277-283.

Palmedo, H.; Guhlke, S.; Bender, H.; Sartor, J.; Schoeneich, G.; Risse, J.; Grünwald, F.; Knapp, FF(Russ)Jr.; Biersack, H.J.; (2000), Dose escalation study with rhenium - 188 hydroxyethylidene diphosphonate in prostate cancer patients with osseous metastases. Eur. J. Nucl. Medicine, 27, 123130.

Bagatti, D.; Cantone, M.C.; Giussani, A.; Ridone, S.; Birattari,C.; Bonardi, M.L.; Groppi, F.; Martinotti, A.; Morzenti, S.; Gallorini, M.; Rizzio, E., (2005), Analytical and radioanalytical quality control of purity and stability of radiopharmaceutical compound [186gRe]Re-HEDP for bone metastases pain palliation. J. Radioanal. Nucl. Chemistry, 263, 515520.

Knapp, FF(Russ)Jr.; Beets, A.L.; Guhlke, S.; Zamora, P. O.; Bender, H.; Palmedo, H.; Biersack, H-J., (1997), Availability of rhenium-188 from the alumina-based tungsten - 188 / rhenium - 188 generator for preparation of rhenium - 188 - labeled radiopharmaceuticals for cancer treatment. Anticancer Research, 17, 1783-1796.
Knapp, FF(Russ)Jr. (1998), Rhenium-188 A generatorderived radioisotope for cancer therapy. Cancer Bioth. Radiopharmaceuticals, 13, 337-349.

Kothari, K.; Pillai, M.R.A.; Unni, P.R.; Shimpi, H.H.; Noronha, O.P.D.; Samuel, A.M., (1999), Preparation, stability studies and pharmacological behavior of [186Re]Re-HEDP. Appl. Rad. Isotopes, 51, 51-58.

Hashimoto, K.; (1998), Synthesis of a 188Re-HEDP complex using carrier-free $188 \mathrm{Re}$ and a study of its stability. Appl. Rad. Isotopes, 49, 351-356.

Hsieh, B-T; Hsieh, J-F; Tsai, S-C; Lin, W-Y; Wang, SJ; Ting, G., (1999), Comparison of various rhenium188-labeled diphosphonates for the treatment of bone metastases. Nucl. Med. Biology, 26, 973-976.

Lam, M.G.E.H.; Klerk, J.M.H. de; Rijk, P.P. van; (2004), 186Re-HEDP for metastatic bone pain in breast cancer patients. Eur. J. Nucl. Med. Mol. Imaging, 31:1, S. 162-S170.
Received: July 04, 2005; Revised: July 14, 2005; Accepted: August 01, 2005. 